\title{
Conflicto espacial, exclusión y espacio público en la centralidad urbana de Xalapa, Veracruz'
}

\author{
Conflito espacial, exclusão e espaço público no centro urbano de Xalapa, \\ Veracruz \\ Spatial conflict, exclusion and public space in the urban center of Xalapa, \\ Veracruz
}

Mauricio Hernández Bonilla, Sonia Gómez Gómez

Universidad Veracruzana, Xalapa Enríquez, Veracruz, México

\section{Resumen}

En la última década se ha suscitado un incremento de intervenciones físicas para la transformación del espacio público del centro histórico en la ciudad de Xalapa, Veracruz. El presente trabajo analiza principalmente el carácter y orientación de la intervención pública en la transformación y mejoramiento del espacio público. El análisis se lleva a cabo a través de estudios de caso, tomando como ejemplo dos escenarios cuyo análisis socio-urbano permite discutir las lógicas de transformación de parte del sector gubernamental en asociación con el sector privado y como estos cambios son percibidos por el usuario cotidiano. Así se pone en evidencia como los procesos están dominados por el poder de grupos minoritarios, y no por los intereses de la ciudadanía, lo que afecta el sentido de comunidad, la inclusión y la función pluralista y democrática del espacio público.

Palabras clave: Espacio público. Centro histórico. Conflicto socio-urbano. Exclusión social. Apropiaciones urbanas.

\section{Resumo}

Na última década, tem-se um incremento da quantidade de intervenções físicas para a transformação da espacialidade pública do centro histórico na cidade de Xalapa, Veracruz. Neste trabalho, discute-se, principalmente, o caráter e a orientação da atuação pública para transformar e melhorar o espaço público urbano. A análise foi realizada por meio de estudos de caso, usando como exemplo dois cenários cuja análise sociourbana permite discutir as lógicas de transformação do governo em parceria com o setor privado e como essas mudanças são percebidas pelos cidadãos. Assim, é evidenciado como esses processos estão dominados pelos interesses de grupos minoritários, e não pelos interesses da cidadania, afetando o sentido de comunidade, a inclusão e a função pluralista e democrática do espaço público.

Palavras-chave: Espaço público. Centro histórico. Conflito sociourbano. Exclusão social. Dotações urbanas.

\footnotetext{
${ }^{1}$ Este artículo surge del trabajo de investigación realizado en el Posgrado en Arquitectura, línea ciudad y territorio de la Facultad de Arquitectura de la Universidad Veracruzana-Xalapa y del proyecto SEP-CONACYT 180749 titulado "Políticas públicas y la transformación del espacio público en la ciudad Mexicana del s. XXI"
}

MHB es PhD, e-mail: mauricio.hernandez.bonilla@gmail.com SGG es Ma Arch, e-mail: sonia200887@gmail.com

urbe. Revista Brasileira de Gestão Urbana (Brazilian Journal of Urban Management), 2015 set./dez., 7(3), 281-294 


\section{Abstract}

Physical interventions to transform the public spatiality of historical centrality in Xalapa City, Veracruz have been increased in the past decade. This work analyzes the character and orientation of public interventions to transform and improve the urban public places. The case study was carry out with a research tool using two scenarios, which social-urban analysis allows to discuss the governmental intentions that, in association with private sector, reset the already mentioned spatialities. The research empirical results show that these processes area are dominated by a minority groups of interest over the citizenship. The whole situation affects the community sense, inclusion and pluralist function and public space democracy.

Keywords: Public space. Historic center. Social-urban conflict. Social exclusion. Urban appropriations.

\section{Introducción}

A comienzos del siglo XXI el contexto urbano mexicano ha presentado un gran número de intervenciones de transformación y reconfiguración de sus espacios públicos. En el caso particular de la Ciudad de México los cambios en la fisonomía de su centro histórico han derivado en estudios socio-urbanos, liderados por Duhau \& Giglia (2004), Ziccardi (2008), Ramírez Kuri (2009) y Carrión (2012), entre otros autores. Estos trabajos nos han alertado sobre la creciente gentrificación, boutiquización ${ }^{2}$ y decadencia del patrimonio histórico que dichas restructuraciones acarrean, reestructuraciones que se logran con ayuda de capital privado, cuyas formas de apropiación generan conflictos de intereses entre los diversos actores. Entre los aportes que hacen los autores mencionados, en el tema por hacer ciudad, se invita a reconsiderar la cantidad y calidad de estudios urbanos realizados acerca del territorio mexicano.

Con el objetivo de contribuir en el debate sobre el espacio público desde una narrativa del conflicto espacial generado en los procesos de mejoramiento físico, se analizan dos escenarios situados en la ciudad de Xalapa-Enríquez, Veracruz. Durante la última década dicha ciudad ha sido objeto de intervenciones urbanas públicas centrales, con iniciativa y participación de actores tanto públicos como privados. Las reconfiguraciones espaciales sufridas por la ciudad responden, en mayor medida, a intereses de grupos y sectores minoritarios. Esto supone la emergencia de una autoridad cada

\footnotetext{
${ }^{2}$ Factor urbano donde tiene como característica la eliminación de la población residente para dar paso a los usos del suelo más rentables y exclusivos (comercios, hoteles, restaurantes, bajo la lógica boutique) (Carrión, 2007).
}

vez más condescendiente con el interés económico que un sector privado tiene sobre las áreas públicas.

De esta manera, el principal objetivo de este artículo es analizar el enfoque y orientación que las intervenciones, tanto gubernamentales como las del sector privado, tienen en el mejoramiento, uso y apropiación de los espacios públicos del centro histórico Xalapeño, dentro de los procesos de renovación y revitalización. A través de este estudio, se pone de manifiesto que la participación de diversos actores, tanto públicos como privados, van reconfigurando la habitabilidad espacial hacia formas que tienden más a la exclusión y privatización, algo cada vez más frecuente en la producción urbana contemporánea.

\section{Lo público y el centro: su transformación y conflictos}

El espacio público ideal, ha sido históricamente identificado como vía e imagen de unidad y equidad para cada uno de los ciudadanos, en su derecho de expresarse y habitarlo, buscando establecer en dicho espacio el "bien común". En este discurso hegemónico que pretende materializar un espacio accesible a todos los individuos, sin importar las desigualdades sociales y económicas, generalmente se considera el espacio público por su connotación de valor democrático por excelencia. Sin embargo, es importante recalcar, que el espacio público nunca ha sido totalmente inclusivo, ni ha sido totalmente accesible a todos los sectores y usuarios de la ciudad. En realidad, los espacios públicos urbanos han servido, a través del tiempo, dependiendo de la cultura y región donde se encuentren, para acomodar actividades que benefician a unos y excluyen a otros. Esto conlleva a que el espacio 
público sea generalmente un espacio de conflicto, lucha y contestación como lo han visualizado diversos analistas e investigadores (ej. Mitchell, 1995; Low, 2000). Generalmente, se presentan diversas visiones e intereses económicos, sociales, políticos y simbólicos, y de dicha diversidad surgen desacuerdos sobre cómo las ciudades y sus componentes urbanos deben ser materializadas (Bentley, 1999). Por lo tanto, como argumenta Van Deusen (2002), el espacio público es siempre un espacio de conflicto y representa una lucha sobre quién lo controla, quién tiene acceso a él y quién determina su imagen y constitución.

En la actualidad, diversos autores exponen "el fin del espacio público" (Sorkin, 1992) o la existencia de un nuevo "espacio híbrido" (Nissen, 2008); por otro lado, otros como Akkar (2005) advierten sobre la pérdida de "publicidad" del espacio público cuando es el capital y los intereses del sector privado los que reestructuran los espacios públicos de la centralidad. Estudios recientes, como el de Carmona (2012), sugieren que la importancia del debate sobre las relaciones entre lo público y privado en los procesos y cambios urbanos, no debe acentuarse en conocer a quién le pertenece, quién lo mantiene, si es público, si es privado... sino en saber cómo funciona para sus usuarios del día a día, como parte de la ciudad en general, además de saber qué derechos ciudadanos se mantienen en dichos espacios.

En el caso del Estado Mexicano, debido a su interés por globalizarse y globalizar sus centralidades urbanas, ha ido surgiendo durante las últimas décadas un creciente interés, por parte de sectores y grupos económicamente fuertes, en formar parte de la transformación y producción de las centralidades históricas urbanas. En dicha transformación hay una tendencia a mercantilizar el espacio urbano y atraer nuevos residentes que acaban desplazando a los sectores más populares y vulnerables. Por otro lado, por primera vez en la urbanidad mexicana, se ha puesto mucho énfasis en los programas públicos dirigidos a la revitalización de los espacios públicos, tal como el "Programa de Rescate de Espacios Públicos". Sin embargo, son los investigadores del Programa de Mejoramiento Barrial (Mier y Terán et al., 2012) -impulsado y ejecutado en las áreas del Distrito Federal- quienes afirman que el cambio de las condiciones materiales de los espacios no garantiza necesariamente transformaciones democratizadoras.

En este sentido, la "recuperación de los centros históricos" (Carrión, 2012) y/o el "rescate del espacio público" frecuentemente ha generado exclusión y desigualdad social para la población menos favorecida, al operar bajo una dinámica que capitaliza el suelo público para una minoría y descapitaliza de "ganancias" a la mayoría. En consecuencia, se presenta el fenómeno de gentrificación a través del cual se visibiliza el cambio radical sufrido en la zona histórica, en donde no sólo se elimina el vínculo del patrimonio con su historia -pasada y presente-, sino que también se daña la cultura y finalmente se agrede al turismo, mostrando una realidad falsa (Rojas, 2012, p. 544). En el caso particular de México, la actualización de sus políticas espaciales a las demandas económicosociales que exige la mundialización (Fidel et. al., 2012) ha representado todo un reto, por la complejidad que implica modernizar un país con tan altos niveles de desigualdad y exclusión social (Martínez Quintana, 2006). Además, actualmente, la principal inversión proviene de la iniciativa privada, generando una concentración de hoteles, restaurantes, bares y establecimientos similares (García Espinosa, 2005, p. 216).

Partiendo de las reflexiones anteriores, resulta esencial cuestionarnos cómo los procesos de reconfiguración espacial del espacio público en una ciudad como Xalapa, a la luz de las tendencias contemporáneas de revitalización urbana de las centralidades, han conseguido alterar la asistencia, actividades y expresiones espontáneas de los grupos sociales que asisten, usan y reclaman el espacio público. Acercándonos a este interés, podríamos mencionar el trabajo de Ramírez Kuri (2009) sobre las percepciones, apropiaciones y prácticas sociales sobre el Centro Histórico de Coyoacán en la capital mexicana. Por otro lado, en el trabajo de Duhau \& Giglia (2008) se identifica el espacio público del centro histórico como "el espacio disputado" por la gran competencia que existe entre funciones, usos y percepciones. Esto coincide con Carrión (2005), que define el centro como un espacio público "objeto del deseo" asumiéndolo como proyecto y deseo, con sus roles de encuentro, representación y disputa en términos sociales y urbanos. Así, los centros históricos suelen considerarse como espacios de conflicto entre dos sectores poblaciones: un sector tradicional que vive en él y de él y un sector "moderno" que desea rehabilitarlo (Hiernaux 2010, p. 39). Sirviéndonos de estos conceptos visualizaremos su desarrollo en nuestro caso de estudio. 


\section{El caso Xalapa, Veracruz}

La fundación de Xalapa, tuvo lugar en el año 1313, época en que fue fundada Tenochtitlán (H. Ayuntamiento de Xalapa, 2008a). La formación de la ciudad se remonta a tiempos prehispánicos, su estructura física fue erigida a partir de los cuatro barrios fundadores: Xallitic, Techacapan, Tehuanapan, y Tlalnecapan (H. Ayuntamiento de Xalapa, 2008a). Actualmente, son Xallitic y Techacapan quienes además de estar inscritos en la centralidad de la urbe, persisten en la memoria local de los actuales moradores del sitio. Llegada la época colonial, la ciudad de Xalapa presentó un trazado urbano de "plato roto" con un esquema concéntrico de jerarquización socio-espacial, que constituye una característica típica de las ciudades hispánicas en América (Jaramillo, 2012). El fenómeno de la emigración de las élites de las zonas centrales hacia la periferia es un fenómeno recurrente en muchos centros urbanos del orbe y también presente en Xalapa. En consecuencia, cabe destacar que la expansión del territorio, así como la definición de actividades del centro de la ciudad, responde a intereses del sector poblacional con más altos ingresos.

En la última década, programas públicos federales como "Hábitat" o "Rescate de Espacios Públicos" para el mejoramiento del entorno urbano han cobrado gran relevancia en el país. De tal manera que en los últimos años, los gobiernos locales se han preocupado cada vez más por el mejoramiento y revitalización del espacio público en las ciudades mexicanas, y el caso de la capital Veracruzana no es ajeno a esta dinámica. Así, durante los últimos periodos de las diversas administraciones locales ${ }^{3}$, se ha promovido la renovación urbana de diversas calles, plazas y parques de la ciudad.

Por ejemplo, el gobierno de David Velazco Chedraui (2008-2010) promueve, con su plan de Desarrollo Municipal, "una ciudad limpia" que busca hacer de Xalapa una ciudad más sustentable, con parques, jardines y espacios públicos. Dicho plan tiene como objetivo dotar a Xalapa de una infraestructura de

\footnotetext{
${ }^{3}$ Los gobiernos locales de la última década en la ciudad de Xalapa han sido de procedencia Priista (Partido Revolucionario Institucional). A diferencia de otras entidades federativas, en el estado de Veracruz no ha existido una alternancia política. En los últimos 15 años sólo ha habido un gobierno de procedencia política diferente a la del Partido Revolucionario Institucional.
}

servicios cuya planificación y ejecución la reafirmen como núcleo de desarrollo sustentable -a nivel metropolitano y regional-, mejorando el cuidado y manejo de recursos, áreas naturales y espacios públicos (Xalapa, 2008b). Así se establece que los parques existentes en Xalapa deben consolidarse como espacios de convivencia y recreación para atraer más visitantes en beneficio del Municipio y su gente. Además, este plan establecía que en las colonias se crearían nuevos parques urbanos en donde la gente pasee, se ejercite y se divierta, y así los espacios públicos se dignificarían con la colaboración de los Gobiernos Estatal y Federal (Xalapa, 2008 b, p. 106). Según los documentos oficiales, el gobierno municipal intentó atender la fuerte demanda ciudadana de parques recreativos y espacios dignos con el fin de que los niños no interrumpan el tránsito automovilístico, o los jóvenes se inmiscuyan en actividades antisociales.

Por otro lado, el plan desarrollado por la alcaldía de Elizabeth Morales García (2011-2013) incluye "la utilización del espacio público" enfocándose sobre todo en el uso y apropiación del espacio. Se busca el fomento de la cultura, específicamente la cultura urbana pública, ya que este gobierno identificaba la inexistencia de una cultura de apropiación de los espacios públicos, rebasada por el repentino auge de los espacios públicos virtuales, lo que provoca una falta de identidad tradicional local y de compromiso con el cuidado del espacio público (Xalapa, 2011, p. 36-37). De tal manera que este gobierno municipal promovió el mantenimiento, reparación y construcción de los espacios públicos a través de acciones públicas relacionadas con la seguridad, respeto y apropiación del espacio público junto con una actitud cívica sana y participativa (Xalapa, 2011, p. 43).

En relación a la participación de los diversos sectores de la sociedad, dentro de las estrategias del gobierno de David Velazco Chedraui, se habla de "[...] integrar a la sociedad en los programas y las acciones del Ayuntamiento para el cuidado y rescate de los parques, jardines y unidades deportivas [...]", y durante el posterior gobierno encabezado por Elizabeth Morales, el Plan Municipal se hace más específico y menciona la inclusión de la iniciativa privada en la configuración de los espacios públicos:

Diseñar, convocar y concursar proyectos para consolidar el paisaje urbano en plazas y jardines temáticos, invitando a participar al público, a 
universidades y a la iniciativa privada (con la modalidad de adopción y cuidado temporal de estas áreas para su mantenimiento). (Xalapa, 2011, p. 69).

Durante estos gobiernos, siguiendo los planes de desarrollo municipal, se realizaron acciones importantes para el mejoramiento, mantenimiento y construcción de nuevos espacios públicos. Así, durante la alcaldía de David Velazco Chedraui, en la zona centro se construyó el Mirador de los Lagos (Figura 1), se rehabilitó el Parque 5 de Febrero, y se renovó parte del callejón González Aparicio. Por otro lado, durante la administración de Elizabeth Morales se peatonalizó la calle de Miguel Palacios, se revitalizaron las calles de J.J. Herrera y el Dique como parte del paseo turístico Centro histórico -los Lagos, se peatonalizaron las calles de Alcalde y García y de Miguel Arrieta, y se remodeló el Mercado del Barrio San José, entre otros. Igualmente, durante estas administraciones se construyeron y mejoraron diversos espacios públicos en la periferia de la ciudad, tales como parques, canchas deportivas y áreas recreativas en diversas colonias populares.

\section{Aproximación metodológica}

El estudio del espacio público se aborda a través del estudio de casos como estrategia de investigación en la ciudad de Xalapa, Veracruz, México. La selección de los contextos de análisis se realizó mediante el acotamiento del perímetro de estudio: el centro histórico de la ciudad. Se identificaron dos espacios públicos que han

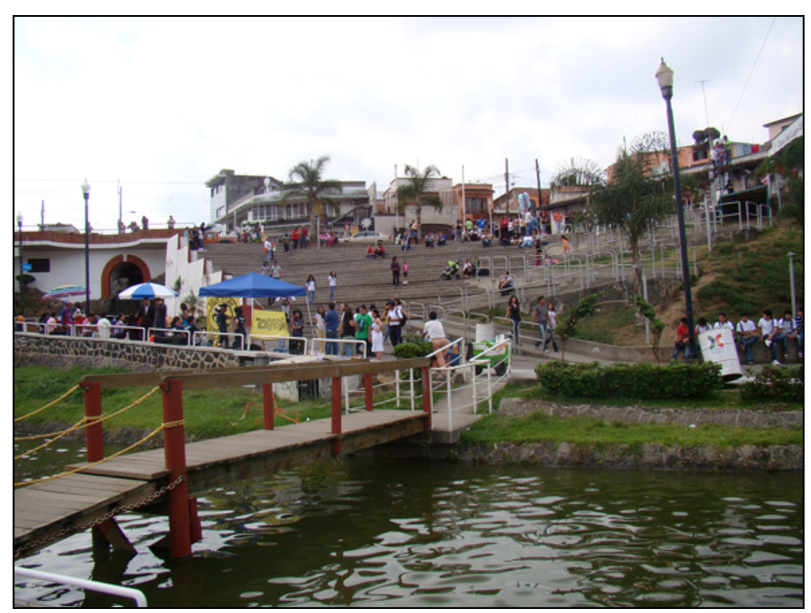

Figura 1 - Mirador del paseo "Los Lagos" Xalapa, Ver. Fuente: De los autores (2014). sido objeto de alteraciones físicas: la calle González Aparicio y la calle Alcalde y García. En estos casos, la disputa, el conflicto y competencia entre diversos actores e intereses, emerge a través de la apropiación física, las significaciones y/o representaciones sobre las transformaciones realizadas.

Se utilizaron diversas estrategias tanto cualitativas como cuantitativas para la recolección de datos: realización de entrevistas a informantes clave, aplicación de cuestionario/encuesta realizada a usuarios de los espacios, y observación ${ }^{4}$ continua y sistemática de ambos sitios, con el fin de distinguir tanto los diversos usuarios de los espacios como las actividades que se realizan. Por otro lado, para conocer cuáles son las percepciones de los ciudadanos -cómo valoran, aprecian y viven el espacio público-, se aplicaron cuestionarios ${ }^{5}$ y se realizaron entrevistas en profundidad a diversos usuarios e informantes clave; entrevistas que de alguna forma reflejaran los diversos intereses, sectores o grupos involucrados en la configuración física y social del espacio -ocupado por usuarios, habitantes, comerciantes, vendedores ambulantes, empleados de la zona, y funcionarios de gobierno. Finalmente, se hizo una revisión de artículos periodísticos y comunicados de prensa -fuentes primarias-, para conocer cómo sucedieron diversos hechos, y cuáles son las opiniones y acontecimientos relacionados con los cambios y transformaciones espaciales. Así, el principal objetivo fue explorar cómo las diversas actividades y acciones de apropiación espacial dan cuenta de sus acciones las cuales, dependiendo de percepción de los diversos actores, representan abusos y/o sobre-control ejercido en los diversos procesos de transformación y uso. Finalmente, ciertos actores excluyen y/o desplazan a otros, con lo que aumentan los desequilibrios y conflictos sociales y disminuye la equidad e igualdad de acceso y participación a los espacios públicos de la ciudad.

\footnotetext{
${ }^{4}$ Se realizó la observación de cada sitio durante dos semanas, la cual fue plasmada en un reporte fotográfico y un reporte de actividades en bitácora, durante los días lunes, miércoles, viernes, sábado y domingo en horario matutino (entre 8 a.m. y 10 a.m.) y vespertino (entre 2 p.m. y 6 p.m.).

${ }^{5}$ Se realizaron seis entrevistas por cada uno de los cinco días mencionados y se repitieron nuevamente dos semanas posteriores, por lo tanto se realizaron alrededor de 60 cuestionarios
} 


\section{La apropiación "exclusivista" del Callejón González Aparicio}

\section{La transformación y el conflicto espacial}

El Callejón de González Aparicio se localiza dentro delárea del antiguo barrio Tehuanapan y forma parte del primer cuadro del centro histórico de la ciudad de Xalapa y de la zona de monumentos históricos (México, 1990). La fisonomía de este espacio público presenta rasgos que exaltan la topografía y materiales constructivos propios de la región. Se le otorgó el nombre de callejón ${ }^{6}$ por sus dimensiones, una condición que en algunos puntos imposibilita el tránsito vehicular; sin embargo las áreas de mayor extensión (donde llega alcanzar un máximo de 6 metros) sirven de acceso al único estacionamiento privado de la calle, además de servir como parque público.

Su utilidad como suelo comercial es el que impera, debido a que el uso residencial ha sido desplazado por el comercial. La mayoría de los locales comerciales son arrendados y los propietarios todavía son los antiguos moradores de las casonas, hoy convertidas en bares y restaurantes. De tal manera que hoy en día -a partir del cambio de uso de suelo-, en los alrededores de este espacio público, surgieron disputas sociales por la apropiación que los propios comerciantes hicieron del área pública. En este mismo tenor, el periódico "Al Calor Político" registra el comienzo de estas actividades de apropiación por parte del sector privado y para beneficiarse económicamente de dicha calle:

En pleno centro histórico de la capital del estado se da el cierre de un antiguo callejón que hoy es transformado por un particular para ampliar los establecimientos comerciales de su propiedad [...] la empresaria Cristina de Arcángeles arbitrariamente y sin mediar sesión de cabildo decidió cambiar el nombre por nuevo "Callejón La Perla”, cubrió el empedrado con planchas de cemento, colocó barandales para ampliar sus cafeterías, colocó estructuras metálicas arriba para techar con domos y prácticamente canceló la circulación en esta vía pública que de un ancho mayor a los tres metros y medio se redujo a un metro y hasta a 70 centímetros de ancho [...]. (González, 2008).

\footnotetext{
${ }^{6}$ Paso estrecho y largo entre paredes, casas o elevaciones del terreno (Real Academia Española, 2012).
}

El relato anterior da cuenta de cómo el centro y su patrimonio es "explotado" por parte del sector privado para aumentar sus ganancias, como García Espinosa (2005) y otros autores como Hiernaux (2010) comentan:

Los comercios nuevos, las actividades recreativas no tradicionales, las nuevas pautas constructivas y la destrucción progresiva del patrimonio [...] estrategias modernizadoras que llegaron para imponerse y transformar de fondo los barrios tradicionales. (Hiernaux, 2010, p.37).

Los empresarios de la calle González Aparicio, apoyados por las autoridades, fueron pioneros en transformar espacio público, generando fenómenos de exclusión y tendencias de privatización dentro de la urbanidad Xalapeña. Consecuentemente, los predios aledaños (casonas viejas) fueron adecuando sus instalaciones para uso comercial en horario nocturno. Ante estas acciones, surgieron grupos inconformes (usuarios) que reclamaban (principalmente en la prensa) dicho espacio público, del que ahora se había apropiado un sector puramente comercial. Además es evidente que las autoridades locales pretenden proyectar una imagen apropiada para fortalecer la vocación turística del centro. El siguiente comentario publicado en la prensa local da cuenta de ello:

"Defiende Méndez Acosta ampliación comercial en callejones"

[...] el director de Desarrollo Urbano, Fernando Méndez Acosta, no sólo defendió las obras de ampliación comercial que se están haciendo en el callejón González Aparicio, a pesar de que limitan el paso peatonal con la colocación de barandales [...] lo que se hizo obedece a que el alcalde David Velasco giró instrucciones para que se haga de Xalapa una ciudad turística [...]. (Rojas, 2008).

Lo comentado por el Director de Desarrollo Urbano es un argumento que, de alguna manera, defiende las reclamaciones de los inconformes con la apropiación del callejón llevada a cabo por los comerciantes. Finalmente, también se evidencia la relación de las administraciones locales con el sector privado. Así como González Gómez (2010) argumenta que el Estado asume un rol preponderante, y que no se debe soslayar su sumisión ante inversiones privadas que pueden afectar los intereses del patrimonio local. 


\section{La percepción del cambio}

Con base en el surgimiento de reclamaciones, identificación de disputas y la defensa del sector privado por parte de las autoridades, en la investigación empírica se preguntó a los entrevistados (usuarios transeúntes) si consideraban que las transformaciones espaciales llevadas a cabo en la centralidad respondían a las necesidades de toda la población. Durante la realización de entrevistas a los principales usuarios del callejón (jóvenes), la respuesta fue bastante limitada. Pocos recordaban que el Callejón González Aparicio había sido un espacio público abierto y sin ninguna barrera física que impidiera el libre tránsito peatonal y el flujo vehicular para la carga y descarga de mercancías. Quizá la falta de memoria responda al hecho de que nunca fue un espacio de gran identidad y fuerza pública, por ser un callejón. Este mismo hecho pudo permitir que se convirtiera en un espacio endeble y así pudiera ser apropiado y transformado en otras actividades. Las respuestas fueron bastante complejas, llegando los encuestados a argumentar que las ampliaciones de comercios respondían a las necesidades de la población y esa era la razón de la gran afluencia de visitantes. Sin embargo a la pregunta de si el callejón de González Aparicio era un lugar de encuentro y convivencia para todos los estratos sociales, la respuesta fue negativa en un $90 \%$ de los entrevistados. Lo que demuestra que ahora el espacio se percibe como accesible para tan solo ciertos grupos sociales.

Al detectarse una escasa convergencia de diversos grupos sociales en el sitio, se requirió a los transeúntes y paseantes para que mencionaran a los principales usuarios del lugar. La pluralidad de calificativos con los que se denominaba a los diversos grupos de usuarios requirió de un cuestionario con una categorización heterogénea de usos y actores, de horarios y días de la semana. Para los consultados el sitio representa tres funciones: recreativas, de encuentro y como vía de comunicación hacia las calles e inmuebles circundantes. Las dos primeras representan los usos que la calle ofrece en horario nocturno, excepto los lunes que cierran los negocios, y donde los usuarios son de estatus socio- económico alto.

Al enfatizar las apreciaciones respecto al mobiliario urbano del sitio y las transformaciones que se le han otorgado (barandas y planchas de concreto sobre la original piedra braza), los ciudadanos entrevistados se encuentran en un 75\% disgustados con las barandas instaladas de manera permanente en el sitio. Por otra parte, ese mismo $75 \%$ dijo estar conforme con las rampas de hormigón que construyeron en el inicio y final de ese pasillo comercial. Otro aspecto observado durante las visitas de campo, es la nula presencia de personas con movilidad limitada, ni tan siquiera individuos con vehículos no motorizados recorren el callejón. Para los entrevistados dicha situación era comprensible porque hay aspectos que imposibilitan o dificultan la movilidad: el material de piedra braza y la estrechez del pasillo comercial, destinado exclusivamente para el tránsito peatonal. Sin embargo el 25\% restante, que dice estar de acuerdo con las alteraciones físicas del espacio público, justificó su opinión diciendo que para ellos el espacio ahora se mostraba "más vivo" y "que había más vitalidad", situación que, cabe resaltar, concuerda con la de los usuarios de bares y restaurantes.

\section{El espacio exclusivo}

Es importante analizar que los jóvenes de clase media-alta son los principales usuarios del callejón, como espacio de esparcimiento y entretenimiento, $y$ que usan dicho espacio en el horario de la tarde-noche. Los bares y cafés instalados en la vía pública (Figura 2) están dirigidos a este grupo poblacional, ya que en los interiores se encuentran diseños vanguardista y contemporáneos que invitan a un sector más exclusivo a sentirse relajado y a gusto dentro de un ambiente acorde a sus intereses. Estos usuarios ocupan esta área de manera intensiva, ya que resulta ser un espacio fuertemente controlado por los comerciantes que a través de sus diversos códigos establecen el tipo de usuario que es bienvenido a este espacio urbano, como lo manifestó un entrevistado. "En el bar BECO el cadenero sólo te permite entrar si te ves bien vestido, a un amigo le negaron la entrada porque llevaba tenis [...] además para mí es muy caro permanecer ahi"7.

Evidentemente, cualquier persona que no tenga los recursos económicos para cruzar las barandas, sentarse y consumir en las mesas instaladas, no puede-simple y sencillamente- acceder a este espacio "público". De tal manera, que el Callejón de González Aparicio se convierte en un espacio dominado por el consumo, dirigido por los comerciantes y utilizado por

\footnotetext{
${ }^{7}$ (Informante, Febrero 21 de 2014, 12:00 hrs.)
} 

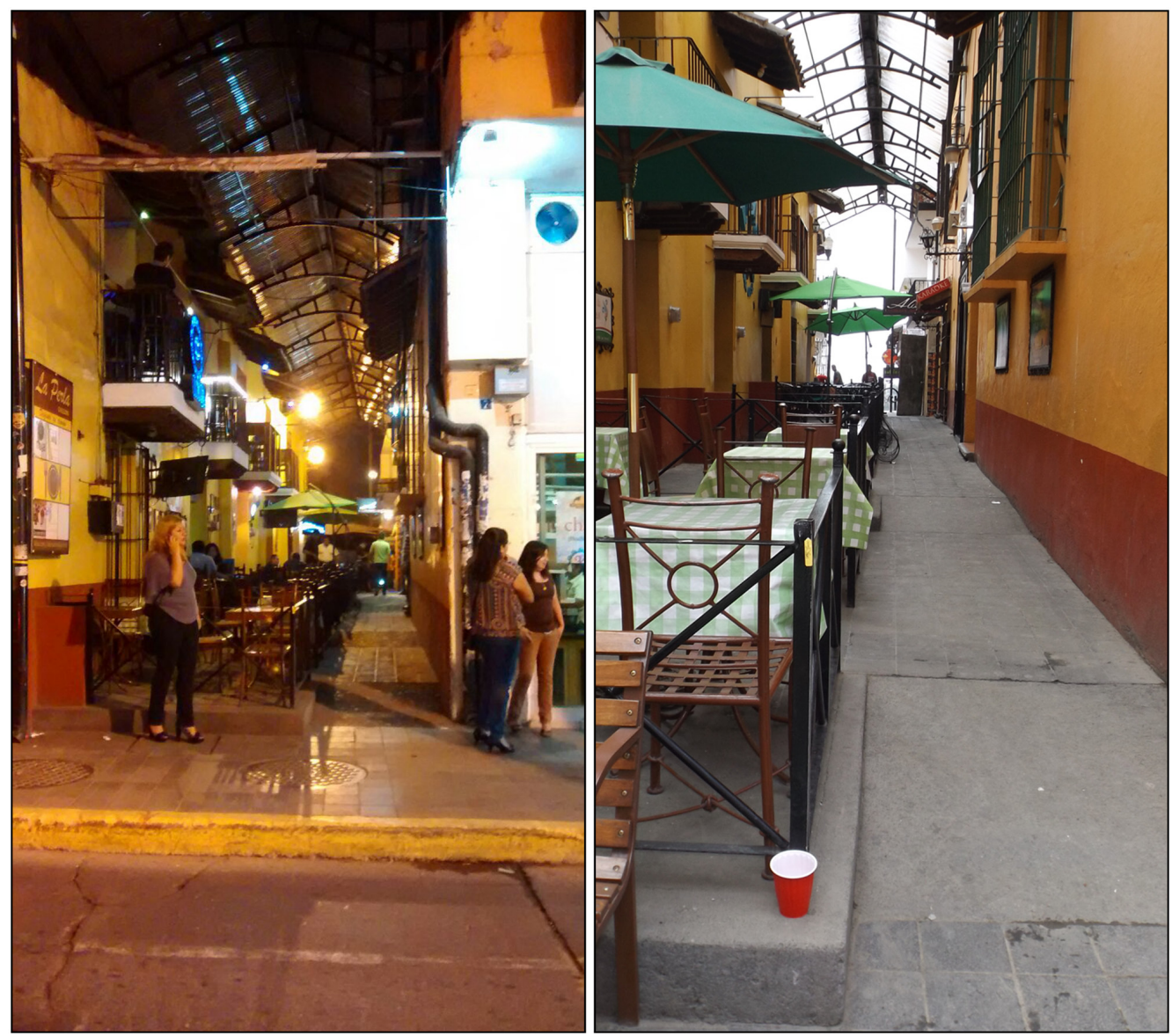

Figura 2 - Apropiaciones sobre el Callejón González Aparicio, Xalapa, Ver. Fuente: De los autores (2014).

aquellos que contribuyen a mercantilizar, reinventar y -de alguna forma- privatizar el espacio público. De esta manera se imponen usos, conductas, códigos y espacios con los que se crean espacios segregacionistas y excluyentes, una curiosa aportación a la identidad urbana de esta ciudad Veracruzana.

Lo sucedido en el callejón González Aparicio coincide con lo que Carmona (2012, p. 128) identifica en su clasificación del espacio público contemporáneo: espacio público "exclusivista o elitista", es decir aquel que no permite el acceso a grupos con alguna discapacidad, ancianos o personas de un nivel socioeconómico medio-bajo. También de acuerdo con el mismo autor (Carmona 2012, p. 129) lo podríamos clasificar como un espacio público "parroquial" porque se lo apropian ciertos grupos en particular, y cualquiera que deambule por el sitio se podría sentir ajeno -como un extraño o como un turista- y no como parte del espacio, quedando supeditado a la manera en que encaje y/o se identifique con el sitio y los demás usuarios.

\section{De lo "popular a lo selecto" en la Calle Alcalde y García}

La transformación y el conflicto espacial

La calle Alcalde y García se localiza dentro del barrio Techacapan y, al igual que le sucedió a cada uno de los barrios autóctonos ${ }^{8}$, le fue impuesta la erección de un templo durante la época de la Colonia. En la actualidad, la mixtura de usos de suelo y actividades le ha conferido el reconocimiento de ser uno de los barrios más emblemáticos y tradicionales de Xalapa. En el barrio se encuentra el cuartel de policías, la parroquia de San José y el mercado "Alcalde y García".

\footnotetext{
${ }^{8}$ Xalapa es una de las poblaciones más antiguas del estado, en el siglo XIV se establecieron en ella cuatro grupos indígenas; Totonacas, Chichimecas, Toltecas y Teochichimecas, fundando cuatro poblados; Xallitic, Techacapan, Tecuanapan y Tlalnecapan, respectivamente. (Xalapa, 2008).
} 
Pese a su relevancia social, económica e histórica, no fue sino hasta finales del año 2010, durante la administración del ex alcalde David Velasco Chedraui, cuando se focalizó la mirada en el barrio San José. La intervención resultó ser un proyecto urbano de gran envergadura para el centro de la ciudad. Se realizaron trabajos de remodelación del mercado. Además de que a los vendedores de la calle Alcalde y García se les reubicó en la Central de Abastos -un sitio alejado del centro de la ciudad. El entonces Director de Desarrollo Económico Municipal explica las acciones tomadas:

Aproximadamente 30 locatarios fueron ya reubicados, por lo que hay confianza en que pronto ese inmueble pueda convertirse en un corredor turístico. El proyecto es construir un corredor en donde haya algunas cafeterías, lugares educativos, bibliotecas, espacios culturales. [...] Se beneficiará a los comerciantes, pues la central de abasto está teniendo una importante difusión para no perjudicar sus ventas. No se trata de que los locatarios de San José salgan afectados [...]. (García, 2010).

Nuevamente, en este extracto de la entrevista realizada a un funcionario de la ciudad, se evidencia lo que la crítica académica dice sobre tendencia que tiene el estado y sus autoridades a crear una imagen diferente a la ya existente en las centralidades históricas, como ya comentó García Espinosa (2005) En el caso de Xalapa, la creación el "corredor turístico" se vuelve un objetivo primordial, negándole el carácter popular que durante décadas ha caracterizado esta zona.

En este caso, el conflicto y la disputa de la transformación espacial de la calle se originó por la inconformidad del sector comercial despojado, quejándose de que antes de las intervenciones de "revitalización" aquel había sido su espacio de trabajo e incluso residencia en el barrio Techacapan:

Integrantes de la organización Vendedores Independientes Veracruzanos (VIVE) denunciaron que los locales del mercado "Alcalde y García" están siendo entregados a empresarios. [...] "No es posible que los mercados populares sean transformados para beneficio de quienes tienen mucho dinero. Ese lugar debería ser para beneficio de la sociedad, del pueblo Xalapeño y no de unos cuantos", dijo [...] el mercado "Alcalde y García" debe ser para el pueblo Xalapeño [...]. (León, 2011).
En los hechos descritos, se percibe un fenómeno de gentrificación, ya muy mencionado en la literatura del tema (ej. Martínez Ramírez, 2015). En nuestro caso los vendedores populares representan esos habitantes populares de bajo perfil socioeconómico que ejercen una actividad comercial popular dirigida a grupos de nivel socioeconómico medio-bajo. Finalmente, estos vendedores luchan para no ser desplazados por empresarios de élite: los nuevos residentes que atraerán a nuevos usuarios y visitantes también de élite. En total contradicción con nuestras reflexiones anteriores, la ex alcaldesa Elizabeth Morales afirmaba que el eje central de las obras era y había sido la seguridad, preservación de la cultura y sustentabilidad ${ }^{9}$.

\section{La percepción del cambio}

Durante muchos años la calle había servido como estacionamiento para los usuarios y comerciantes del mercado y trabajadores de los inmuebles vecinos. El material de piedra braza y la localización de la calle había hecho de esta vía pública un sitio prescindible para el tránsito vehicular, factores que estimulaban el uso casi total de la calle, principalmente por parte de los comerciantes, como un estacionamiento público. No obstante, con la remodelación y reconfiguración de estas vías públicas advino una nueva función y uso: la "peatonalización". De esta manera, el proyecto incluía la incorporación de nuevo mobiliario urbano como jardineras, cubierta de acero con láminas de policarbonato, bancas, mojones y cadenas con los que limitar el tránsito vehicular y delimitar el área pública y privada.

Las áreas donde antiguamente se localizaban los operarios de mudanzas (los cuales ahora trabajan en la embocadura de la calle), hoy en día son para beneficio casi exclusivo de los nuevos comercios -cafeterías, bares y restaurantes. Contradictoriamente a lo que buscaba el gobierno local y según comentan los vecinos, se ha incrementado la presencia de vagabundos en la calle y ahora es común observarlos alrededor de restaurantes y bares pidiendo monedas.

Durante las entrevistas se introdujo el tema de la función del espacio. Un aspecto que de manera general se relacionó con actividades recreativas, y específicamente

\footnotetext{
${ }^{9}$ Coordinación General de Comunicación Social del Estado de Veracruz, Noviembre 11 de 2012.
} 
como sitio de trabajo y de abastecimiento. Así mismo se identificaron tres significados, que además de dotar de carácter al espacio subyace tras de todo comportamiento humano: la seguridad, la equidad y la pertenencia. Para el 50\% de la población consultada la presencia de policías da una imagen de seguridad y protección dentro del sitio, mientras que la otra mitad expresó su desacuerdo, refiriéndose a ellos como "individuos de quienes hay que protegerse ${ }^{\prime 10}$. $\mathrm{Al}$ interrogar si consideraban que cualquier individuo, de cualquier estatus social, género y edad, podría asistir y convivir en este sitio, el 95\% de los consultados dieron una respuesta aprobatoria. Los consultados identificaron también a quienes frecuentaban la calle Alcalde y García. El 90\% dijo que no era frecuentado por vendedores ambulantes, mientras que el $10 \%$ restante dijo que estos aparecían en horario nocturno, y con su área de trabajo alrededor de los comensales. El 10\% de los encuestados dijo que los artistas callejeros frecuentaban el lugar pero en horario diurno; y poniendo voz a uno de estos artistas oímos cuál es su percepción sobre la equidad del sitio:

Aquí ya viene otro tipo de gente. Pero no importa, igual seguimos viniendo quienes siempre hemos estado aquí, nosotros por ejemplo, nos gusta venir a comer cada que tenemos un poco de dinero al mercado, y en quincena nos piden canciones en los locales de comida [...]. Cuando llegaron estos nuevos restaurantes pensamos que sería una fuente de trabajo pero, no es cierto... rara vez nos dan permiso los meseros de tocar, y si nos dan chance la gente que está en los restaurantes nos ponen caras o ni siquiera nos dejan tocar [...]. (Alfredo Galván,-músico callejero- 20 de Octubre, 12:00 hrs.).

"Al interrogar a los entrevistados su opinión respecto a la transformación de la calle Alcalde, el $60 \%$ la calificó como "buena"; sin embargo el $40 \%$ restante la valoró como "regular" y "mala". Esta última opinión fue dada en su mayoría por vecinos residentes en la calle Justo Sierra, y una reducida población de adultos mayores que acuden asiduamente a este espacio. Transcribo una opinión puntual:

Yo no sé de quién fue la idea de tener aquí bares... yo no tengo problemas con los restaurantes, como el "Asadero Cien" o el "Bola de Oro", de hecho en ocasiones voy ahí con mi hija. Pero en las entrevistas y talleres que el gobierno realizó

\footnotetext{
${ }^{10}$ Comunicación personal, Octubre 10 de 2013.
}

con nosotros, y los locatarios del mercado, expresamos que esa zona donde están ahora los nuevos negocios era un sitio inseguro. Nos dijeron que iba a haber restaurantes familiares [...] Ahora están estos bares, ique hasta se encuentran justamente atrás de la iglesia!, Nos quitaron las camionetas de mudanza, que era bien inseguro por las noches, y en su lugar nos pusieron un par de negocios pero ahora con borrachos y malvivientes. ¿¿Qué clase de solución, no?! [...]. (Alejandra Flores, 17 de Octubre, 15:00 hrs.).

\section{El espacio exclusivo}

En entrevista con el ex Director de Obras Públicas ${ }^{11}$, uno de los principales responsables de las transformaciones realizadas, se le preguntó la forma de participación del sector privado en los procesos de planificación y ejecución de proyectos, participación que dicho funcionario municipal negó que hubiera existido. En cuanto a la relación y acuerdos con particulares para la concesión y adecuación de las áreas rehabilitadas para el comercio se le interrogó: ¿Durante qué etapa del proyecto se tuvo conocimiento del destino de esos locales, y quienes serían los nuevos inquilinos del espacio? En respuesta nuestro informante declaró que: “[...] la administración pasada ya había acordado la participación de privados para la revitalización del espacio, de hecho tengo entendido hubo pláticas con algunos empresarios; pero, la certeza de los negocios que se establecerían aún no se tenía [...]."12 Finalmente el ex Director de Obras Públicas acabó el diálogo sobre el objeto y las intenciones de cada una de las intervenciones desarrolladas en el centro de la ciudad con las siguientes palabras:

El objeto de estas transformaciones, en los espacios públicos de nuestros centros, es que la gente acuda a ellos con la misma demanda como sucede en "Plaza Américas"13. Es evidente el éxito de los centros comerciales en nuestra ciudad, el incremento de estos inmuebles lo

11 Arq. Roberto Sánchez Vega de la administración municipal 2010-2012, entrevistado en 2013.

12 Comunicación personal, Octubre 08 de 2013.

13 Centro comercial localizado sobre la carretera Federal Xalapa-Veracruz. 
explica. (Comunicación personal, 08 de Octubre de 2013).

En estos argumentos del director de obras públicas podemos elucidar que la autoridad local tenía la intención de crear un espacio que atrajera el sector poblacional de un nivel socio-económico medio-alto, sector que ha preferido trasladar sus actividades recreativas y de consumo que antes se desarrollaban en la centralidad histórica y ahora en los ambientes "inventados y de consumo": las plazas comerciales localizadas en las periferias de la ciudad.

Tal y como lo relata la población del sitio, tanto las funciones como la fisonomía del lugar invitan o excluyen a los habitantes. Las intervenciones físicas de revitalización y peatonalización es fuente de conflicto para los moradores; y es que, de la misma manera en que fue impuesta la transformación, originada y dirigida por intereses de las autoridades, también se impuso la convivencia con nuevos habitantes. Para la autoridad el proyecto obtuvo una aceptación generalizada, aunque no tanto para aquellos que fueron y continúan siendo habitantes del espacio. El proceso de asimilar e identificarse con el nuevo espacio público resulta un tanto complejo. La "Calle Alcalde y García" se ha llenado de mojones, cadenas, jardineras, macetones, mobiliario privado y una estructura de acero para los comensales de los nuevos restaurantes, configurándose así lo que hoy se denomina "Plaza Gastronómica" (Figura 3). Esto representa de alguna manera el polo opuesto a lo que en esencia ha sido la zona de San José con su característico mercado: su comercio popular de frutas, verduras, venta de flores y cocinas económicas. Sin duda alguna, lo que se vive en Xalapa es la "Gentrificación Cultural", una forma particular de globalización que reconfigura el centro de la ciudad mediante prácticas de socialización y
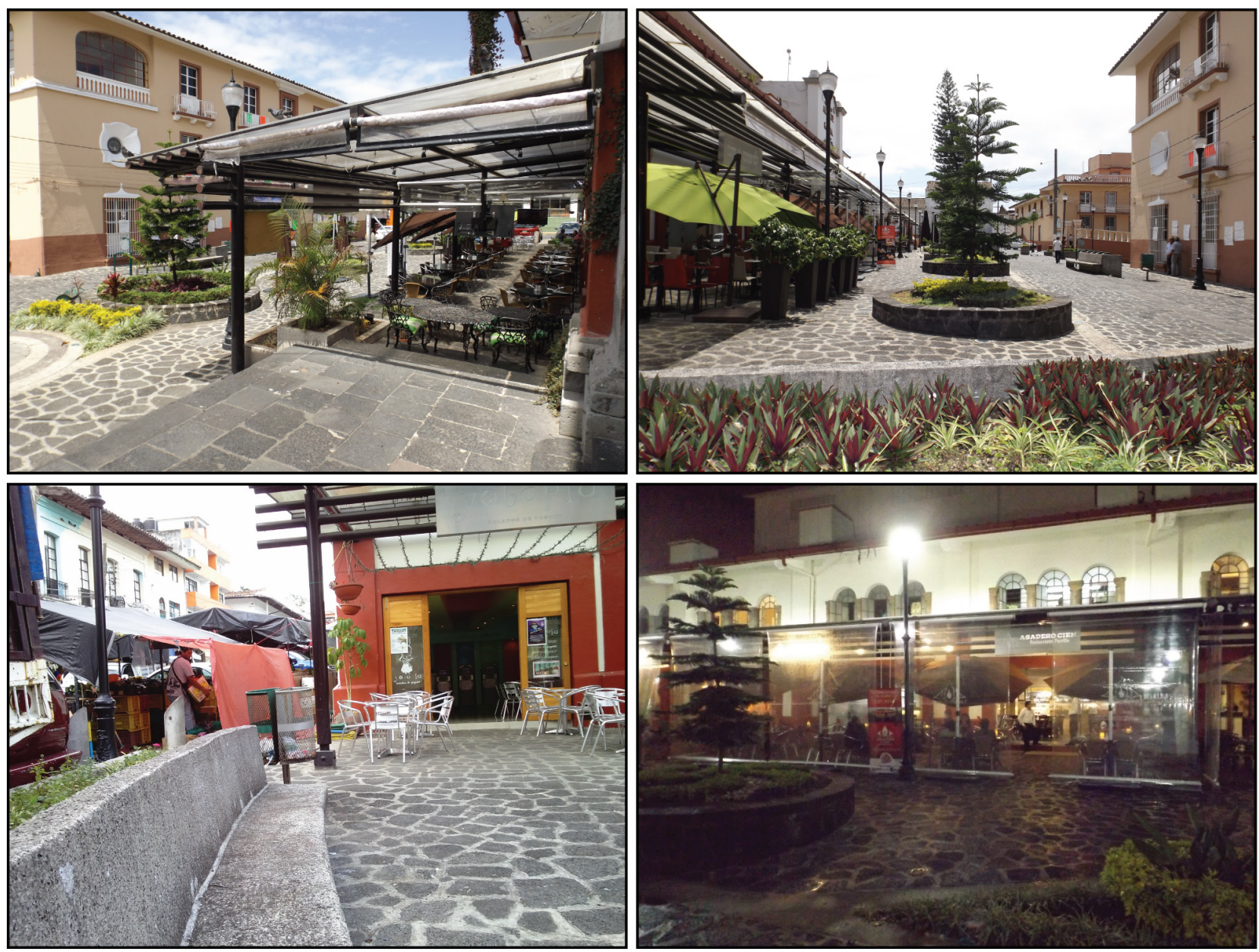

Figura 3 - Los nuevos restaurantes y calle peatonal de Alcalde y García, Xalapa, Ver. Fuente: De los autores (2014). 
pautas de consumo distintas a las habituales (González Gómez 2010, p. 292). Es innegable que los usuarios, comerciantes y visitantes han sido desplazados y ahora, en ese mismo edificio donde antes estaba el mercado popular, se ubican lujosos restaurantes para una clientela de clase media-alta: el espacio público ha sido apropiado y privatizado en una micro-escala. En palabras de Hiernaux (2010, p. 39), el límite entre la "ciudad espectáculo" y la "ciudad farsa" es muy estrecho: las necesidades de rentabilidad y el deseo de producir actividades "comodificables" a corto plazo conllevan emprender ciertas maniobras, tales como disfrazar las actividades "mal vistas" con el color y el estilo del barrio.

\section{Reflexiones finales}

A partir de los estudios realizados en los dos espacios públicos localizados en la centralidad de Xalapa, Veracruz, y tras el análisis de los cambios espaciales y consecuentemente sociales, se pone en manifiesto la complicidad -entre el sector privado y los gestores públicos- en la búsqueda de beneficios económicos, y el fortalecimiento de los lazos entre ambos actores, en la medida que existe una "reciprocidad lucrativa" a través de la gestión del espacio público. Para entender esta reflexión primero hay que reconocer que cada una de las intervenciones urbanas -realizadas en la calle González Aparicio y la calle Alcalde y García- siguen las políticas urbanas que, desde los últimos años del siglo XX, tiene por objeto reorientar el desarrollo inmobiliario privado y público hacia el centro de la ciudad, con el fin de repoblar, redensificar y aprovechar la infraestructura y equipamiento existente de esta zona (Flores \& Bornazou, 2012) creando espacios turísticos, con nuevos inquilinos y turismo de élite.

La investigación realizada en el caso Xalapa nos lleva a reflexionar en el malestar e indignación que producen estas áreas urbanas ante la falta de integración social; la alteración de su valor democrático todavía no ha sido entendida ni asumida por el total de la ciudadanía. La ciudadanía desarraigada de lo que para ellos "siempre les perteneció", "donde siempre permanecieron", es la que de manera inmediata decide, de forma explosiva y sin titubeos, denunciar la arbitrariedad con la que se manejó la intervención de la calle Alcalde y García. La arbitrariedad observada en la calle González Aparicio fue denunciada por los medios de comunicación -fuentes primarias-, el más importante y único portavoz de la denuncia, crítica y desafección experimentada ante los usos y abusos cometidos sobre territorios públicos en beneficio de particulares, con la connivencia de la entidad pública gestora.

La producción de espacios donde se excluye a una mayoría y se privilegia a la minoría elitista, a través de su escenografía y códigos de comportamiento, representa un foco de inestabilidad ciudadana que alimenta la frustración de sus habitantes. Todo lo dicho aquí queda plasmado en la disputa por el uso del suelo: una contienda de los ciudadanos xalapeños, prevaleciendo la mayoría como residentes y habitantes del área, contra los intereses materializados en la esfera privada por los grupos de élite. Es ahí, una vez más en el espacio público, donde se efectúa la lucha y disidencia por lo impuesto y lo reprimido, a través de apropiaciones, usos, funciones, marginaciones y auto-marginaciones producidas por los significados otorgados al sitio. Quienes dicen ser habitantes del espacio afrontan las lastimosas decisiones y concesiones que el Gobierno otorga a la esfera privada en detrimento de la esfera pública. De tal manera que en Xalapa el sector económico pudiente en connivencia con el sector político gerente deciden compartir beneficios a la hora de reestructurar la centralidad urbana, sin que la mayoría de la población o el propio Estado se hagan conscientes de las vicisitudes que acarreará a posteriori el problema de la desigualdad y la exclusión social.

\section{Referencias}

Akkar, Z. M. (2005). Questioning the "Publicness" of public spaces in postindustrial cities. Traditional Dwellings And Settlements Review, 16(2), 75-91.

Bentley, I. (1999). Urban transformations: power, people and urban design. London: Routledge.

Carmona, M. (2012). Capital spaces: the multiple complex public spaces of a globalcity. London: Routledge.

Carrión, M. F. (2005). El centro histórico como proyecto y objeto de deseo. EURE (Santiago), 31(93), 89-100. http:// dx.doi.org/10.4067/S0250-71612005009300006

Carrión, M. F. (2007). El financiamiento de la centralidad urbana: el inicio de un debate necesario. In M. F. Carrión (Ed.), El financiamiento de los centros históricos en América 
Latina y el Caribe (1a ed., p. 9-24). Quito: Lincoln Institute of Land Policy.

Carrión, M. F. (2012). Dime quién financia el centro histórico y te diré qué centro histórico es. In A. Ziccardi (Ed.), Ciudades del 2010: entre la sociedad del conocimiento y la desigualdad social (1a ed., p. 517-553). México: Universidad Nacional Autónoma de México.

Duhau E. \& Giglia A. (2008). Las reglas del desorden: habitar la metrópoli. Mexico: Siglo XXI.

Duhau, E., \& Giglia, A. (2004). Conflictos por el espacio y orden urbano. Estudios Demográficos y Urbanos, 19(2), 257-288.

Fidel, C., Di Tomaso, R., \& Farias, C. (2012). Conjunto de ensambles urbanos entre la pobreza y la producción. El municipio de Quilmes, República Argentina. In A. Ziccardi (Ed.), Ciudades del 2010: Entre la sociedad del conocimiento y la desigualdad social (1a ed., p. 861-918). México: Universidad Nacional Autónoma de México.

Flores, S., \& Bornazou, E. (2012). El bando 2: balance de una política de reestructuración urbana en el Distrito Federal. In A. Ziccardi (Ed.), Ciudades del 2010: entre la sociedad del conocimiento y la desigualdad social (1a ed., p. 239278). México: Universidad Nacional Autónoma de México.

García Espinosa, S. (2005). Los centros históricos ¿Una estrategia de sustentabilidad? In Textos del IV seminarioTaller Internacional de la red mexicana de ciudades hacia la sustentabilidad (p. 209-218). Morelia: Universidad Michoacana de San Nicolas de Hidalgo.

García, A. (2010). No saben si habrá 'manita de gato' al mercado San José. Veracruz: Marcha. Recuperado el 10 de abril 2014, de http://www.marcha.com.mx/ edicion/2010-07-09/2393.pdf.

González Gómez, C. (2010). El centro histórico de Querétaro: gentrificación light y vida cultural. In R. Coulomb (Ed.), México: centralidades históricas y proyectos de ciudad ( $\mathrm{p}$. 283-304). Ecuador: Olacchi.

González, A. (2008). Particular cierra el Callejón González Aparicio, en el centro histórico de Xalapa. Veracruz: Al Calor Político. Recuperado el 02 de abril 2014, de http:// www.alcalorpolitico.com/informacion/particular-cierrael-callejon-gonzalez-aparicio-en-el-centro-historico-dexalapa-20738.html\#.U7WhYhY6ZDQ.

Hiernaux, D. (2010). Los centros históricos ¿espacios modernos? (De choques imaginarios y otros conflictos).
In R. Coulomb (Ed.), México: centralidades históricas y proyectos de ciudad (p. 23-46). Ecuador: Olacchi.

Jaramillo, S. (2012). Reflexiones sobre las políticas de recuperación del centro y del centro histórico de Bogotá. In A. R. Óscar (Ed.), El centro tradicional de Bogotá (1a ed., p. 45-108). Colombia: Universidad Externado de Colombia.

León, R. (2011). Denuncian entrega de locales del "Alcalde y García" a empresarios. Xalapa: Diario Xalapa. Recuperado el 10 de Abril 2014, de http://www.oem.com.mx/ diariodexalapa/notas/n1910830.htm.

Low, S. (2000). On the plaza: the politics of public space and culture. Austin: University of Texas Press.

Martínez Quintana, V. (2006). Problemas sociales de género en el mundo global. Madrid: Centro de Estudios Ramón Areces.

Martínez Ramírez, U. (Enero, 2015) Proceso de gentrificación y desplazamiento en el espacio público del centro histórico de la ciudad de méxico. Working Paper Series CONTESTED_CITIES. Recuperado en Marzo de 2015, de http:// contested-cities.net/working-papers/wp-content/uploads/ sites/8/2015/01/WPCC-15006MartinezRamirezUriel_ Gentrificacionyespaciopublico.pdf.

México. Instituto Nacional de Antropología e Historia. (1990, 12 de diciembre).12-19-90 DECRETO por el que se declara una zona de monumentos históricos en la ciudad de Xalapa de Enríquez, Ver, con el perímetro, características y condiciones que se mencionan. México D.F.: Diario Oficial de la Federación. Recuperado el 05 de Junio de 2014, de http://www.gobiernodigital.inah.gob.mx/Transparencia/ Archivos/31_xalapa.pdf.

Mier y Terán, A., Vázquez, I., \& Ziccardi, A. (2012). Pobreza urbana, segregación residencial y mejoramiento del espacio público en la Ciudad de México. In A.Ziccardi (Ed.), Ciudades del 2010: Entre la sociedad del conocimiento y la desigualdad social (1a ed., p. 689-724). Ciudad de México: Dirección General de Publicaciones y Fomento Editorial.

Mitchell, D. (1995). The end of public space? People's park, definition of the public and democracy. Annals of the Association of American Geographers, 85, 108-113.

Nissen, S. (2008). Urban transformation from public and private space to spaces of hybrid character. Urban People, 44(6), 1129-1149.

Ramírez Kuri, P. (2009). Espacio público y ciudadanía en la ciudad de México: percepciones, apropiaciones y prácticas sociales en Coyoacán y su Centro Histórico. México: UNAM. 
Real Academia Española. Diccionario de la Real Academia Española (22. a ed.). Madrid: Real Academia Española. Recuperado en 10 de diciembre de 2012, de http://lema. rae.es/drae/?val=callej\%C3\%B3n.

Rojas, A. (2012). Turismo y patrimonio: la práctica de la verdad. In I. Rigol, \& A. Rojas. (Eds.), Conservación patrimonial: teoría y crítica. La Habana: UH Editorial.

Rojas, R. (2008). Defiende Méndez Acosta ampliación comercial en callejones. México: Diario de Xalapa. Recuperado el 10 de abril 2014, de http://www.oem.com.mx/esto/notas/ n650399.htm.

Sorkin, M. (1992). Variations on a theme park: the new American City and the end of public space. Journal of Architectural Education, 48(1), 65-67.

Van Deusen, R., Jr. (2002). Public space design as class warfare: urban design, the 'right to the city' and the production of Clinton Square, Syracuse, NY. GeoJournal, 58(2-3), 149-158. http://dx.doi.org/10.1023/B:GEJ0.0000010834.17907.5e
Xalapa. (2008a). Antecedentes históricos. Origen precolombino. Xalapa: H. Ayuntamiento de Xalapa. Recuperado el 03 de Mayo de 2014, de http://xalapa.gob.mx/xalapa/ antecedentes-historicos.

Xalapa. (2008b). Plan municipal de desarrollo 2008-2010. Xalapa: H. Ayuntamiento de Xalapa. Recuperado el 05 de Julio de 2014, de http://ordenjuridicodemo.segob.gob. $\mathrm{mx} /$ Estatal/VERACRUZ/Municipios/Xalapa/1Plan.pdf.

Xalapa. (2011). Plan municipal de desarrollo 2011-2013. Xalapa: H. Ayuntamiento de Xalapa. Recuperado el 05 de Julio de 2014, de http://www.xalapa.gob.mx/wp-content/ uploads/2011/08/PMD-XALAPA.pdf.

Ziccardi, A. (2008). Ciudades latinoamericanas: procesos de marginalidad y de exclusión social. In R. Cordera, P. Ramírez, \& A. Ziccardi (Eds.), Pobreza, desigualdad y exclusión social en la ciudad del siglo XXI (1a ed., p. 73-91). Ciudad de México: Siglo XXI.

Recibido: Ago. 11, 2014

Aprobado: Abr. 15, 2015 